\title{
Fabrication, Characterization, and Dye Adsorption Capability of Recycled Modified Polyamide Nanofibers
}

\author{
Bahaa S. Metwally ${ }^{1}$, A. Atef El-Sayed ${ }^{2}$, E.K. Radwan ${ }^{3}$, Asmaa S. Hamouda ${ }^{4}$, M. \\ N. El-Sheikh ${ }^{5}$, Mohamed Salama ${ }^{2 *}$ \\ ${ }^{1}$ Textile Technology Department, Faculty of Industrial Education, Beni-Suef University, \\ Beni-Suef, Egypt. \\ ${ }^{2}$ Textile Research Division, National Research Centre, El Bohouth St, Dokki, Giza, Egypt \\ 12622. \\ ${ }^{3}$ Department of Water Pollution Research, National Research Centre, El Bohouth St, Dokki, \\ Giza, Egypt 12622. \\ ${ }^{4}$ Environmental Sciences and Industrial Development Department, Faculty of Postgraduate \\ Studies for Advanced Sciences (PSAS), Beni-Suef University, Beni-Suef, Egypt. \\ ${ }^{5}$ Mechanical Engineering Department, Beni-Suef University, Beni-Suef, Egypt. Textile \\ Research Division, National Research Centre, El Bohouth St, Dokki, Giza, Egypt 12622.
}

\begin{abstract}
$\mathbf{U}$ TILIZATION of electrospinning technique accompanied by chemical modification as well as, the production of low-cost adsorbent based on polyamide nanofibers is the aim of our current work. The electrospinning parameters (polymer conc, applied voltage, and collector distance) have been studied. The obtained polyamide nanofiber mats were modified with citric acid at various conditions (concentration, temperature and catalyst concentration). The optimum conditions of this modification were investigated by MB uptake efficiency. The obtained data illustrate a positive relationship between citric acid concentration and MB uptake using the modified polyamide nanofiber. The produced adsorbent was well characterized using SEM, ATR-FTIR, and surface area measurement. Scanning Electron Microscopy clarifies minor swelling of nanofibers during the modification process which attributed to the increase in fiber diameter and therefore reduction in the fiber surface area. The adsorption performance of the nanofiber mat was assessed as a function of $\mathrm{pH}$, nanofiber mat dosage, contact time, and initial dye concentration. Kinetics and isotherms analysis were investigated as well. The MB separation capability of the modified PA-nanofiber was considerably higher than that of the PAnanofiber. The kinetic data of both nanofiber mat was better fitted with the pseudo-second-order model. Also, the equilibrium data of PA-nanofiber was better fitted with Freundlich model and Langmuir model in case of the modified PA-nanofiber. The adsorption behavior was favorable chemisorption process as inferred from the kinetics, and the isotherms studies. The results of this study promote the modified PA-nanofiber as a potential adsorption filters for dyeing wastewater decolourization.
\end{abstract}

Keywords: Polyamide fiber, Electrospinning, Citric acid, Adsorption, methylene blue, Wastewater treatment.

\section{Introduction}

A large number of synthetic textile fibers wastes are produced during the stages of production or the disposal of their products after being used. As a result of their non-biodegradable nature, they cause environmental problems (high cost, requires new landfill spaces) [1]. Among the polymer fibers, nylon (nylon 6 and nylon 6.6) fibers are widely used in carpet factories [2]. The recycling of nylon fiber waste has become a major challenge, which can be classified into two approaches: chemical and mechanical. The mechanical recycling based on melting and spinning of the thick filaments, but it is a noneconomical approach due to the unavoidable loss of properties. The chemical recycling route depends on restoring the main components of the polymer, but it also has disadvantages such as purification of monomers and the need for additional chemicals.

On the other hand, Electrospinning is very simple and low-cost approach for producing organic and inorganic nanomaterials. Several studies have addressed the study of the production of PA-nanofiber using Electrospinning. These 
studies show that the solution concentrations of PA6, as well as the terminal carboxylic group of PA66, are of great influence on the electrospinning process [3-6].

In recent years, organic dyes are considered as the main contaminants among water pollutants because they are used in many industries, such as food processing, pharmaceuticals, cosmetics, paper, plastics, leather and textile finishing [7], textile dyes play a major role in the problem. They are produced in around 700,000 metric tons annually. The amount of textile dyes that lost during the dyeing process is about $(2-20 \%)$ of total dye amount in the aquatic environment[8]. Textile dyes are characterized by their strong color, the presence of small amounts of it less than $(1 \mathrm{mg} / \mathrm{L})$ in water leads to coloring this water which prevents sunlight from reaching the living organisms within it [9]. Some dyes and their degradation products have a toxic effect on humans and living organisms [10].

Adsorption is a common effective approach to the removal of dyestuffs used by industries [11]. Due to its low processing cost, high efficiency, ease of handling, flexibility, and simplicity of design [12]. In recent years, nano-materials have great success in improving the adsorption efficiency of dyes, because of their high surface area to unit mass ratios. There have been a lot of studies on nano adsorbents, including nanotubes [13], nanoparticles [14], nano-composites [15] and nanofibers [16]. However, using adsorbents in fine powder form increases the cost of the adsorption process due to the additional cost of separation and safe disposal of exhausted adsorbents [17]. Consequently, nanofibers have attracted the attention as a promising material in filtration or sorption because of their comparatively simple manufacturing, cost-effectiveness, high porosity, large surface-to-volume ratio, easiness of design to get adsorption sites and easiness of separation after treatment [7, 16]. Citric acid (CA) was selected as a modifier because it is a non-toxic acid [18], excellent organic cross-linker [19] and enhances the adsorption capacity of metal ions [20-22] and methylene blue [23].

We have to remember, Polyamide (PA) fiber waste is a cheap product resulted from textile factories. Moreover, up to our knowledge the PA fiber waste nanofibers modified with citric acid has not yet been used for wastewater management. This study aims at recycling of the PA fiber waste by converting it into nanofibers that can be used to remediate dye contaminated aqueous medium. Electrospinning technique was accompanied by chemical modification with citric acid to produce the low-cost nanofibers based on PA. The electrospinning parameters (polymer solution concentration, applied voltage, and collector distance), as well as the conditions of CA modification (CA concentration, curing temperature and catalyst concentration), were studied. The produced adsorbent was characterized using UV-Vis spectroscopy, Fourier-transform infrared spectroscopy (ATRFTIR), scanning electron microscope (SEM) and BET surface area. The adsorption performance of PA (fibers, nanofibers, and modified nanofibers) was assessed and compared under different conditions such as aqueous medium initial $\mathrm{pH}$, adsorbent dosage, contact time, and initial dye concentration. Methylene blue (MB) was used as a model substrate in this study. The kinetics data were modeled using the pseudo-first-order and the pseudo-second-order models. While the equilibrium data were modeled using Langmuir, Freundlich, and Dubinin-Radushkevich (D-R) equations.

\section{Experimental}

Materials

PA66 fiber waste (Mac Carpet Factory, Egypt). PA-fiber waste was washed with a $1 \mathrm{~g} / \mathrm{L}$ solution of a nonionic detergent at $80^{\circ} \mathrm{C}$ for $20 \mathrm{~min}$, rinsed thoroughly with water to remove any surface impurities and then air dried.

Formic acid 90\% (BDH Chemicals, England), anhydrous citric acid (CA) 99.5\% (lobachemie, India), sodium hypophosphite monohydrate SHP (Sigma Aldrich, Switzerland), methylene blue (MB) (Sigma Aldrich, U.S.A) and Alcohol (Fisher Scientific, UK) were used as received.

\section{Electrospinning of Polyamide}

PA-fiber waste was dissolved in formic acid $90 \%$, with different concentrations $(15,18$ and 24 $\% \mathrm{wt} / \mathrm{wt})$, by stirred at room temperature until a homogeneous solution was obtained. The solution was poured into a $10 \mathrm{~mL}$ plastic syringe, a high voltage power supply (Glassman U.S.A) was used to apply different voltages (10 and $20 \mathrm{KV})$. The needle tip-collector distance was (15 and 25 $\mathrm{cm}$ ) and flow rate of solution was $0.2 \mathrm{~mL} / \mathrm{hr}$., it was adjusted using a syringe pump (NE-4000 Programmable Syringe Pump, U.S.A).

\section{Modification of polyamide nanofiber with citric acid}

An aqueous solution of CA was prepared by dissolving different amounts $(1,3,6,8$ and 15 $\% \mathrm{wt} / \mathrm{wt})$ of CA in a mixture solution from $30 \%$ alcohol and $70 \%$ distilled water with stirring. Different amounts of SHP (2, 4, 8 and $15 \%$ wt/ wt) as a catalyst were used. The produced PAnanofiber were immersed in the aforementioned modification solutions for $30 \mathrm{~min}$, after that, the 
PA-NF mats were dried in an oven at $80^{\circ} \mathrm{C}$ for 5 min. till constant weight. The dried mats were cured at different temperature $(90,105,120$ and $130{ }^{\circ} \mathrm{C}$ ) for $5 \mathrm{~min}$. The cured nanofiber mats were washed with distilled water to remove nonreacted $\mathrm{CA}$.

\section{Optimization of modification conditions}

The ideal conditions for modifying the PAnanofiber with CA such as citric acid concentration, curing temperature and catalyst concentration were investigated. This investigation was based on the adsorption efficiency of PA-nanofiber toward methylene blue. The adsorption experiments were executed in $250 \mathrm{~mL}$ conical flask with $100 \mathrm{~mL}$ MB solution and then agitated in a shaking water bath (MaXturdy18, DAIHAN Scientific Co, Korea) at $26^{\circ} \mathrm{C}$ and $120 \mathrm{rpm}$.

At each modification parameter, a dry modified sample $(10 \mathrm{mg})$ was added to $100 \mathrm{~mL}$ of $5 \mathrm{mg} / \mathrm{L}$ methylene blue solution pre-adjusted to $\mathrm{pH} 7$ and shook well for $90 \mathrm{~min}$ at room temperature. The solution initial $\mathrm{pH}\left(\mathrm{pH}_{\mathrm{o}}\right)$ and the shacking time were selected based on preliminary experiments. The remaining concentrations of dye in solution were determined by (JENWAY) a UV/VIS Spectrometer at wavelength $664 \mathrm{~nm}$. A standard calibration curve was developed from a series of $\mathrm{MB}$ standards and was linear $\left(\mathrm{R}^{2}=0.99\right)$ from 0 to $30 \mathrm{mg} / \mathrm{L}$. A triplicate measurement was performed to ensure the repeatability of experimental data.

The amount of methylene blue adsorbed by nanofiber was calculated using the following equation (1);

$$
\mathrm{q}_{\mathrm{e}}=\frac{\left(\mathrm{c}_{\mathrm{i}}-\mathrm{c}_{e}\right) \mathrm{v}}{\mathrm{m}}
$$

Where $q_{e}$ is the amount of MB adsorbed per gram of the modified PA-nanofiber at equilibrium (mg/g nanofiber), $\mathrm{C}_{\mathrm{i}}$ and $\mathrm{C}_{\mathrm{e}}$ are the initial and the equilibrium concentrations of dye $(\mathrm{mg} / \mathrm{L})$, respectively. $\mathrm{V}$ is the volume of the solution (L) and $\mathrm{m}$ is the weight of nanofibers used $(\mathrm{g})$.

\section{Characterization}

Scanning electron microscopy (SEM)

The morphology of surface for each of the PA-fiber waste, PA-nanofiberas well as modified PA-nanofiber with citric acid was determined using scanning electron microscopy (Quanta FEG 250) at $20 \mathrm{KV}$. All samples were coated with gold before scanning. The fibers average diameter was determined from SEM images to utilize Image $\mathrm{J}$ software, the results were reported as average values for at least 200 measurements.

ATR-FTIR Spectrum

Attenuated total reflections Fourier transform infrared (ATR-FTIR) was used to determine the functional groups on the dried PA- fiber waste, PA nanofiber as well as modified PA-nanofiber with citric acid. The FTIR study was carried out using a Bruker VERTEX 70 series FTIR spectrometer (Bruker Optics, Germany) with an ATR sampling accessory (MIRacle, Pike Technology, Inc.). In all measurements the resolution used was $4 \mathrm{~cm}^{-1}$ in the range $4000-500 \mathrm{~cm}^{-1}$ at room temperature.

Surface area measurement.

Brunauer-Emmett-Teller (BET) specific surface areas of PA- fiber waste, PA nanofiber and modified PA-nanofiber with citric acid were measured by $\mathrm{N}_{2}$ adsorption-desorption isotherm with a Quantachrome NOVA touch LX4 apparatus (Quantachrome Instruments, USA).

Effects of different conditions on $M B$ adsorption

The roles of solution $\mathrm{pH}_{\mathrm{o}}(3-9)$ and adsorbent dosage $(0.1-1 \mathrm{~g} / \mathrm{L})$ in the adsorption process were explored as a function of contact time. At pre-set time intervals, the nanofiber mat was removed and the concentration of MB in the aqueous phase $\left(\mathrm{C}_{\mathrm{t}}\right)$ was analyzed as stated above. Equations 2 and 3 were used to calculate the removal percentage $(\mathrm{R} \%)$ and the amount of $\mathrm{MB}$ adsorbed per gram of the nanofiber mat at time $\mathrm{t}\left(\mathrm{q}_{\mathrm{t}}(\mathrm{mg} / \mathrm{g})\right)$.

$$
\begin{array}{r}
\mathrm{R} \%=\left(\frac{\mathrm{C}_{\mathrm{i}}-\mathrm{C}_{\mathrm{t}}}{\mathrm{C}_{\mathrm{i}}}\right) 100 \\
\mathrm{q}_{\mathrm{t}}=\frac{\left(\mathrm{c}_{\mathrm{i}}-\mathrm{C}_{\mathrm{t}}\right) \mathrm{v}}{\mathrm{m}}
\end{array}
$$

To analyze the adsorption kinetics, such as mass transfer, physical or chemical reaction and the adsorption rate, two kinetic models: the pseudo-first-order model [24] and pseudo-secondorder model [25] (Eq. 4 and 5, respectively) were used. The pseudo-first-order model assumes that the external diffusion mass transfer is the ratelimiting step [26] while the pseudo-second-order model supposes that chemisorption at adsorption sites rules the adsorption process [27, 28].

$$
\begin{gathered}
\log \left(q_{e}-q_{t}\right)=\log q_{e}-\frac{k_{1} t}{2.303} \\
\frac{\mathbf{t}}{\mathbf{q}_{t}}=\frac{1}{\mathbf{k}_{2} q_{e}^{2}}+\frac{\mathbf{t}}{\mathbf{q}_{e}}
\end{gathered}
$$

where $\mathrm{k}_{1}(1 / \mathrm{min})$ and $\mathrm{k}_{2}(\mathrm{~g} / \mathrm{mg} \mathrm{min})$ are the pseudofirst- and second-order rate constants, respectively.

The adsorption isotherms were obtained by agitating $1 \mathrm{~g} / \mathrm{L}$ of the nanofiber mat with a series of $\mathrm{MB}$ solutions $\left(\mathrm{pH}_{\mathrm{o}}=7\right)$ of different initial concentration $\left(\mathrm{C}_{\mathrm{i}}\right)(5-30 \mathrm{mg} / \mathrm{L})$ for 60 minutes

Egypt. J. Chem. 61, No.5 (2018) 
according to the aforementioned procedure. The obtained data were analyzed by three isotherm models, specifically, Langmuir [29], Freundlich [30], and Dubinin-Radushkevich (D-R) [31] (Eq. 6 to 8 , respectively).

$$
\begin{gathered}
\frac{\mathrm{C}_{\mathrm{e}}}{\mathrm{q}_{\mathrm{e}}}=\frac{1}{\mathrm{q}_{\mathrm{L}} \mathrm{k}_{\mathrm{L}}}+\frac{1}{\mathrm{q}_{\mathrm{L}}} \mathrm{C}_{\mathrm{e}} \\
\log \mathrm{q}_{\mathrm{e}}=\log \mathrm{k}_{\mathrm{F}}+\frac{1}{\mathrm{n}} \log \mathrm{C}_{\mathrm{e}} \\
\ln \mathrm{q}_{\mathrm{e}}=\ln \mathrm{q}_{\mathrm{D}}-\beta \varepsilon^{2}
\end{gathered}
$$

where $\mathrm{q}_{\mathrm{L}}(\mathrm{mg} / \mathrm{g})$ is Langmuir maximum adsorption capacity by monolayer adsorbates, $\mathrm{k}_{\mathrm{L}}(\mathrm{L} / \mathrm{mg})$ is the Langmuir constant related to the energy of adsorption, $\mathrm{k}_{\mathrm{F}}(\mathrm{L} / \mathrm{g})$ and $1 / \mathrm{n}$ are Freundlich constants related to the adsorption capacity and intensity of adsorption, respectively, $\mathrm{q}_{\mathrm{D}}(\mathrm{mg} / \mathrm{g})$ is $\mathrm{D}-\mathrm{R}$ monolayer capacity, $\beta$ is parameter related to sorption energy $(\mathrm{E})$ (where $\left.\mathrm{E}=\frac{1}{(-2 \beta)^{1 / 2}}\right)$ and $\varepsilon$ is Polanyi potential $\left(\varepsilon=\mathrm{RT} \ln \left(\mathbf{1}+\frac{\mathbf{1}}{\mathrm{C}_{\mathrm{e}}}\right)\right.$ where $\mathrm{R}$ is the ideal gas constant $(8.314 \mathrm{~J} \mathrm{~mol} / \mathrm{K})$ and $\mathrm{T}$ is the absolute temperature $(\mathrm{K}))$.

These models explore the adsorbate-adsorbent interactions and the adsorbate distribution from the liquid to solid phase up to equilibrium. Therefore, they explain the interaction mechanism between the adsorbent and the adsorbate and permits optimizing the adsorption process [27, 32, 33].

\section{Results and Discussion}

\section{Electrospinning of Polyamide}

Effect of polymer concentration

Different concentrations (15, 18 and $24 \%$ ) of PA-fibers solution were subjected to electrospinning processes. The effect of the concentration variation on the fibers morphology was investigated and illustrated in Fig. (1, a-c). It was observed that at concentration 15\% (Fig. 1a) no clear fibers formation (i.e. amixture of fibers (average diameter $94.73 \mathrm{~nm}$ ) and fragments droplets) was obtained. This could be attributed to the low surface tension, which prevents stretching the jet through its flight to the collector [34]. Proper nanofibers formation was observed by increasing the concentration of electrospinning solution from 15 to $18 \%$ (Fig. 1b). The obtained nanofibers are also characterized by smooth morphology and absence of beads. This could be regarded to the increase in the entanglements between the chains of polymer in order to make complete stable jet [35]. Increasing the solution concentration to $24 \%$ leads to the enlargement in the average fiber diameter to $267.22 \mathrm{~nm}$ (Figure 1c). Therefore, a concentration of $18 \%$ was used for further experiments.

\section{Effect of distance}

Figure $(1 \mathrm{~b}, \mathrm{~d})$ elucidate the effect of the tip to collector distance on fiber diameter. When the collecting distance was decreased from 25 to $15 \mathrm{~cm}$, a small increase in the fiber diameter was appeared, from 129.29 to $141.66 \mathrm{~nm}$. This could be attributed to the decrease in the flight jet time and therefore the solvent evaporation was decreased [36]. Therefore, the distance was fixed at $25 \mathrm{~cm}$ hereafter.

\section{Effect of voltage}

Figure (1b \& e) shows the relation between the applied voltage through electrospinning process $(10 \& 20 \mathrm{KV})$ and the diameter of the fiber. The SEM images reveal that, as the applied voltage decreased the diameter of the fiber increased $(176.93 \mathrm{~nm})$ also the fibers diameter distribution becomes more heterogeneous in comparison with that obtained at a higher voltage $(129.29 \mathrm{~nm})$. This finding could be explained on the bases of the ability of high voltage to generate and accumulate higher amount of charges on the polymer solution or the Taylor cone surface, leading to the formation of greater electric forces in the jet, as well as more stretching and acceleration of the jet, this results in decreasing the fiber diameter [37].

\section{Modification of the fabricated polyamide nanofiber with citric acid (CA)}

The fabricated PA-nanofiber was modified with CA to improve its adsorption capacity toward basic dyes. Different conditions (CA concentration, curing temperature and catalyst amount) were tested to find the optimal modification conditions. The ability of the modified PA-nanofiber with citric acid to dye uptake is primarily based on the electrostatic attraction between the grafted ionized carboxyl groups on the surface of the nanofibers and the positive charges in the dye molecule [38]. Results obtained laterally with their appropriate discussion follow.

\section{Effect of citric acid concentration}

For a given set of citric acid treatment conditions and within the range examined. Table 1 (run A) clarify the relation between methylene blue uptake by PA-nanofiber at CA concentrations $(1.3,6,8$ and $15 \%)$. It was observed that, the amount of MB dye uptake was increased with the increase in the concentration of CA till $8 \%$. After which, the PA-nanofiber reaches its higher efficiency of MB uptake $(18.68 \mathrm{mg} / \mathrm{g})$ at $8 \%$ citric acid. However, no significant increase was observed by further increase in CA concentration till $(15 \%)$. The improvement in the MB uptake could be discussed in terms of the electrostatic attraction between the grafted ionized carboxyl groups on the nanofiber surface and the positive 


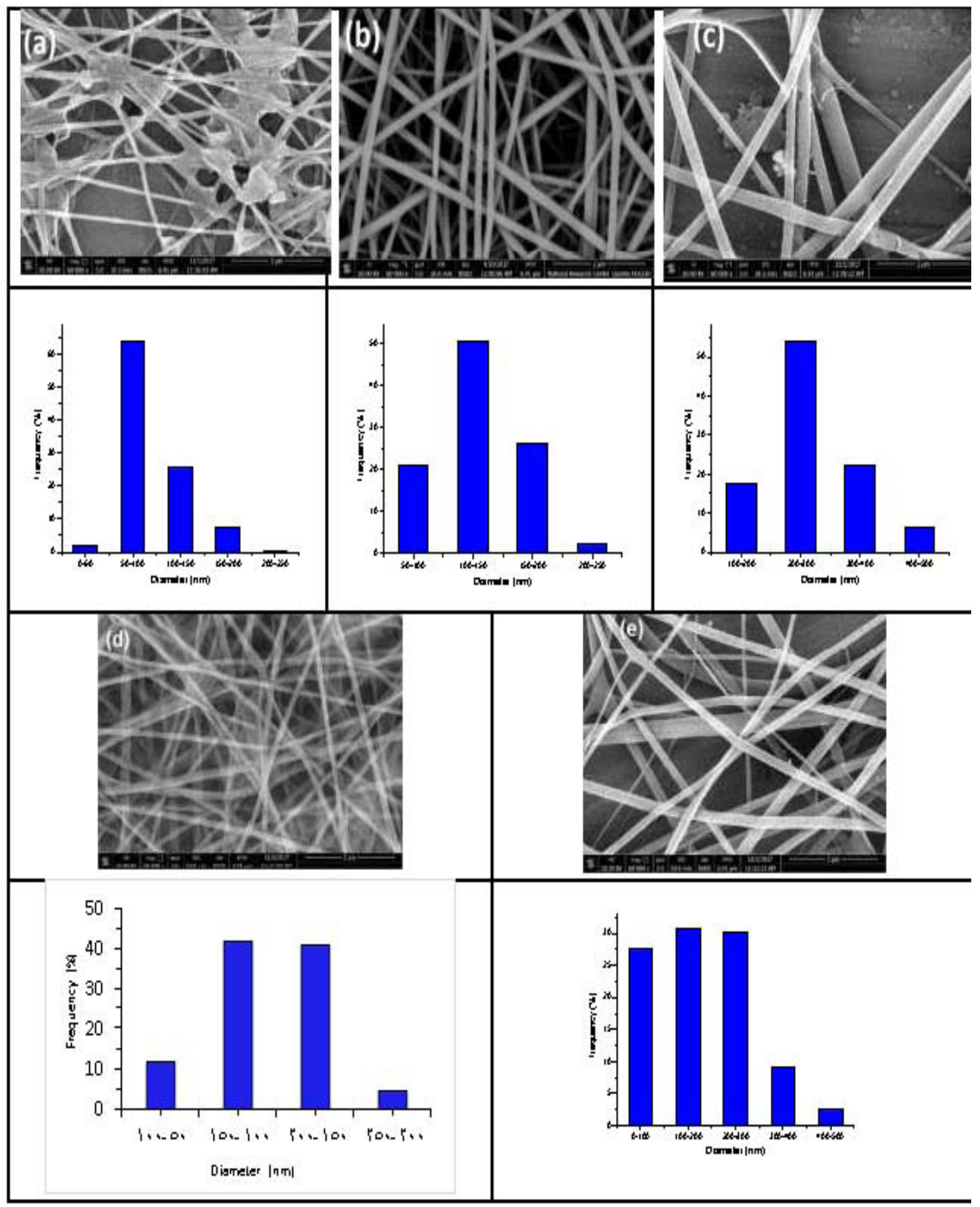

Fig. 1. SEM and diameter distribution of polyamide fiber electrospun fabricated at different electrospinning conditions.

(a) polymer concentration $=15 \% \mathrm{wt} / \mathrm{wt}$, voltage $=20 \mathrm{kV}$, collector distance $25 \mathrm{~cm}$, (b) polymer concentration $=18 \% \mathrm{wt} / \mathrm{wt}$, voltage $=20 \mathrm{kV}$, collector distance $25 \mathrm{~cm}$, (c) polymer concentration $=24 \% \mathrm{wt} / \mathrm{wt}$, voltage $=20 \mathrm{kV}$, collector distance $25 \mathrm{~cm}$, (d) collector distance $15 \mathrm{~cm}$, polymer concentration $=18 \% \mathrm{wt} / \mathrm{wt}$, voltage $=20 \mathrm{kV}$, and (e) voltage $=10 \mathrm{kV}$, polymer concentration $=18 \% \mathrm{wt} / \mathrm{wt}$, collector distance $25 \mathrm{~cm}$.

Egypt. J. Chem. 61, No.5 (2018) 
TABLE 1. MB uptake by modified PA-nanofiber fabricated at different modification conditions.

\begin{tabular}{|c|c|c|c|}
\hline Run & \multicolumn{2}{|c|}{ Parameters } & $\begin{array}{c}\text { MB uptake by PA-nanofiber } \\
\text { (mg/g nanofiber) }\end{array}$ \\
\hline \multirow{5}{*}{ A } & \multirow{5}{*}{ CA Concentrations (\%) } & Untreated & 9.17 \\
\hline & & 1 & 12.26 \\
\hline & & 3 & 14.94 \\
\hline & & 6 & 16.95 \\
\hline & & 15 & 18.72 \\
\hline \multirow{3}{*}{$\mathrm{B}$} & \multirow{3}{*}{ Curing temperatures $\left({ }^{\circ} \mathrm{C}\right)$} & 90 & 17.96 \\
\hline & & 105 & 18.68 \\
\hline & & 120 & 19.99 \\
\hline $\mathrm{C}$ & Catalysis concentrations $(\%)$ & 12 & 27.18 \\
\hline
\end{tabular}

Run A: Untreated and treated with Citric acid concentrations (1,3, 6, 8 and $15 \%)$, Curing temperature $105^{\circ} \mathrm{C}$ and catalyst concentration $8 \%$.

Run B: Curing temperature $90,105,120$ and $130{ }^{\circ} \mathrm{C}$, citric acid concentration $8 \%$ and catalyst concentration $8 \%$.

Run C: Catalyst concentrations $2,4,8$ and $12 \%$, Curing temperature $130{ }^{\circ} \mathrm{C}$ and citric acid concentration $8 \%$.

charges on MB. Therefore, as the number of the free carboxylic groups that are available to react with the basic dye molecules increases, consequently, the efficiency of MB uptake enhanced [38].

\section{Effect of curing temperature}

The curing temperature of the modification process is one of the most important parameters that have a strong impact on the reacted dose (i.e. carboxyl group content on PA-nanofiber) during the grafting step [39]. Table 1 (Run B) summarized the relationship between curing temperature of reaction parameter $\left(90-130^{\circ} \mathrm{C}\right)$ and the $\mathrm{MB}$ uptake by modified PA-nanofiber. Run B displays that, raising the curing temperature from 90 up to 130 ${ }^{\circ} \mathrm{C}$ results in a remarkable improvement in $\mathrm{MB}$ uptake by modified PA-nanofiber from 17.96 to $27.93 \mathrm{mg} / \mathrm{g}$ respectively, suggest that, the curing temperature at $130{ }^{\circ} \mathrm{C}$ provides sufficient energy for the grafting reaction, therefore increasing the carboxyl content on the PA-nanofiber [40]. Above this temperature range the mats are toasted, so temperature $130^{\circ} \mathrm{C}$ is a suitable curing temperature.

\section{Effect of catalyst}

Another important parameter in the grafting reaction of CA on the PA-nanofibers is the catalyst. The grafting of nanofiber mats with citric acid carried out at various catalyst concentrations (2-12 $\%)$, keeping the other variables such as citric acid concentration and curing temperature constant. The data obtained were displayed in Table 1 (Run C), the adsorption efficiency gradually increase with the increase of catalyst content. The maximum MB uptake (27.93 mg/g nanofiber) was obtained when the content of catalyst reached 8 $\%$. In other words, adding sodium hypophosphite monohydrate as a catalyst increases the efficiency of the grafting reaction between CA and PAnanofiber, which is in accordance to the literatures describing the reaction between starch and citric acid [41].

Based on the aforementioned results, the optimum parameters selected for the modification process were $8 \% \mathrm{CA}$, curing temperature at $130{ }^{\circ} \mathrm{C}$ for $5 \mathrm{~min}$ and the catalyst concentration is $8 \%$. These optimum conditions were applied on PA-nanofiber during the modification with $\mathrm{CA}$ and coded with modified PA-nanofiber. The modified PA-nanofibers has been furthermore investigated by SEM to calculate the diameter size distributions (Fig. 2). It clarifies that, a rough and irregular surface of modified PA-nanofibers was observed, indicating that a successful attachment of CA onto PA-nanofibers matrix is obtained. It is worth noting that, the modification process did not distort the fibrous structure of PAnanofiber as clearly seen from the SEM image. It is also observed that, the grafting of CA on the PA-nanofibers lead to enlargement in its diameter, as well as the formation of heterogeneous plateau. This could be regarded to the minor swelling of nanofibers during the modification process which is responsible for fiber diameter increase [42].

\section{ATR-FTIR Spectrum}

To validate the suggestion that PA-nanofiber interacts with citric acid, ATR-FTIR spectrometry measurements were conducted to PA-fiber, PA- 

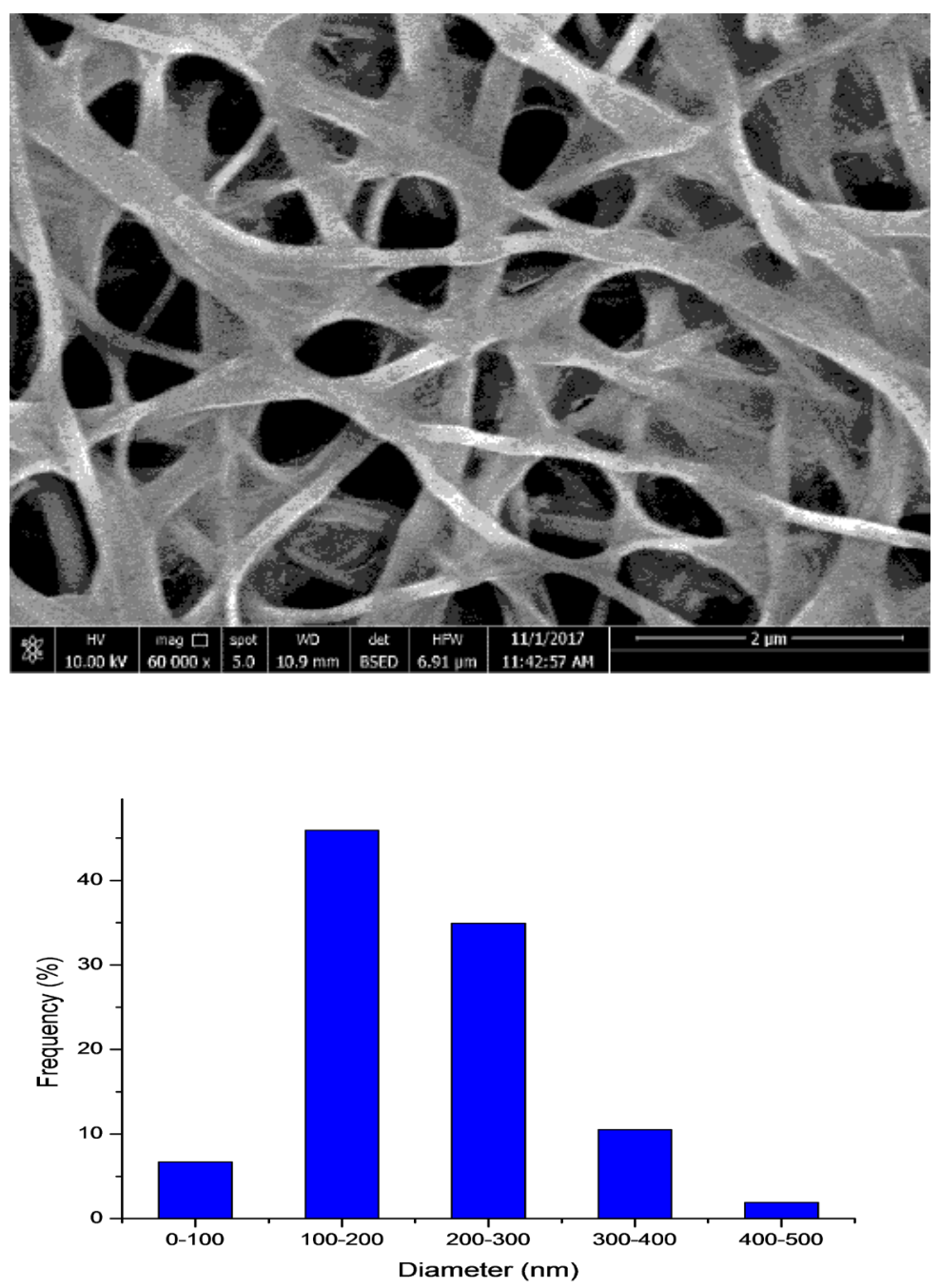

Fig. 2. SEM and Diameter distribution of modified PA-nanofiber with CA.

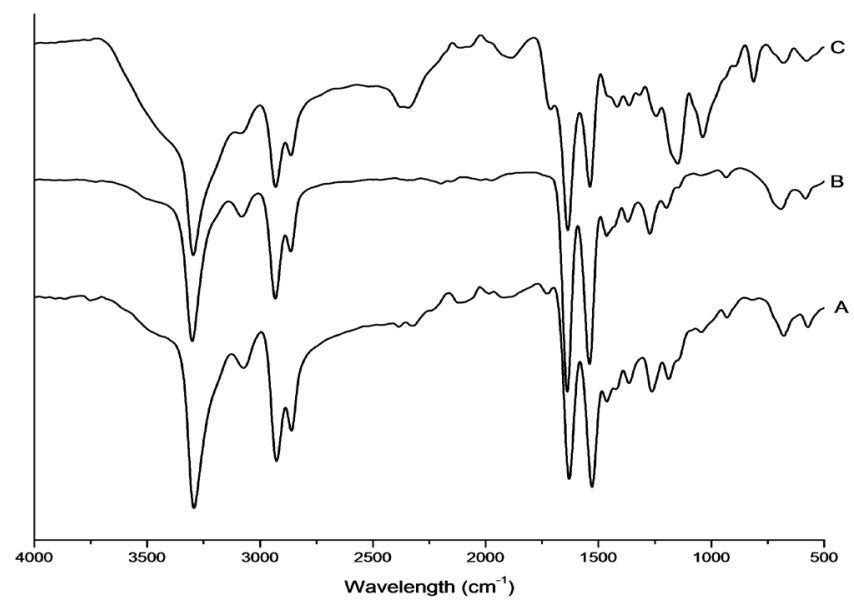

Fig. 3. ATR-FTIR spectra of the polyamide fiber, nanofiber, and modified nanofiber. A: PA-fiber, B: PA-nanofiber and C: modified PA-nanofiber 
nanofiber and modified PA-nanofiber (Fig. 3), and their characteristic vibrations peaks are listed in Table 2. Modified PA-nanofiber (Fig.3C) has two new peaks at 1148.4 and $1038.4 \mathrm{~cm}^{-1}$ which could be referees to the formation of new amide (CO-NH in plane vibration) $[43,44]$. It is also observed that, the existence of the hydroxyl group of CA lets to broadening and distortion of the absorption peak at $3295 \mathrm{~cm}^{-1}$. The proposed grafting reaction of CA onto PA-nanofiber mats was illustrated in Scheme 1.

\section{BET surface area}

Table 3 clarifies the BET surface area of PAfiber, PA-nanofiber and modified PA-nanofiber with CA. It was observed that, a remarkable increase in the value of surface area for nanofiber compared to the regular PA-fiber. However, the surface area of modified PA-nanofiber was reduced from 262.27 to $80.28 \mathrm{~m}^{2} / \mathrm{g}$. We attributed this reduction in surface area to the minor swelling of nanofibers during the modification

TABLE 2. Characteristic vibrations peaks of PA-fiber, PA-nanofiber and modified PA-nanofiber.

\begin{tabular}{|c|c|c|c|}
\hline Characteristics group & $\begin{array}{c}\text { PA-fiber (A) } \\
\left(\mathbf{c m}^{-1}\right)\end{array}$ & $\begin{array}{c}\text { PA-nanofiber (B) } \\
\left(\mathrm{cm}^{-1}\right)\end{array}$ & $\begin{array}{c}\text { Modified PA-nanofiber } \\
\text { (C) }\left(\mathrm{cm}^{-1}\right)\end{array}$ \\
\hline $\mathrm{N}-\mathrm{H}$ stretching vibration & 3292.8 & 3300.5 & 3295.75 \\
\hline N-H Bending vibration & 678.3 & 691.3 & 679.7 \\
\hline $\mathrm{C}=\mathrm{O}$ stretching Vibration & 1629.5 & 1638.2 & 1636.3 \\
\hline $\mathrm{N}-\mathrm{H}$ Bending vibration & 1528.3 & 1539.8 & 1536.9 \\
\hline$-\mathrm{CH}_{2}$ - stretching Vibration & 2926.4 & 2932.2 & 2930.3 \\
\hline
\end{tabular}
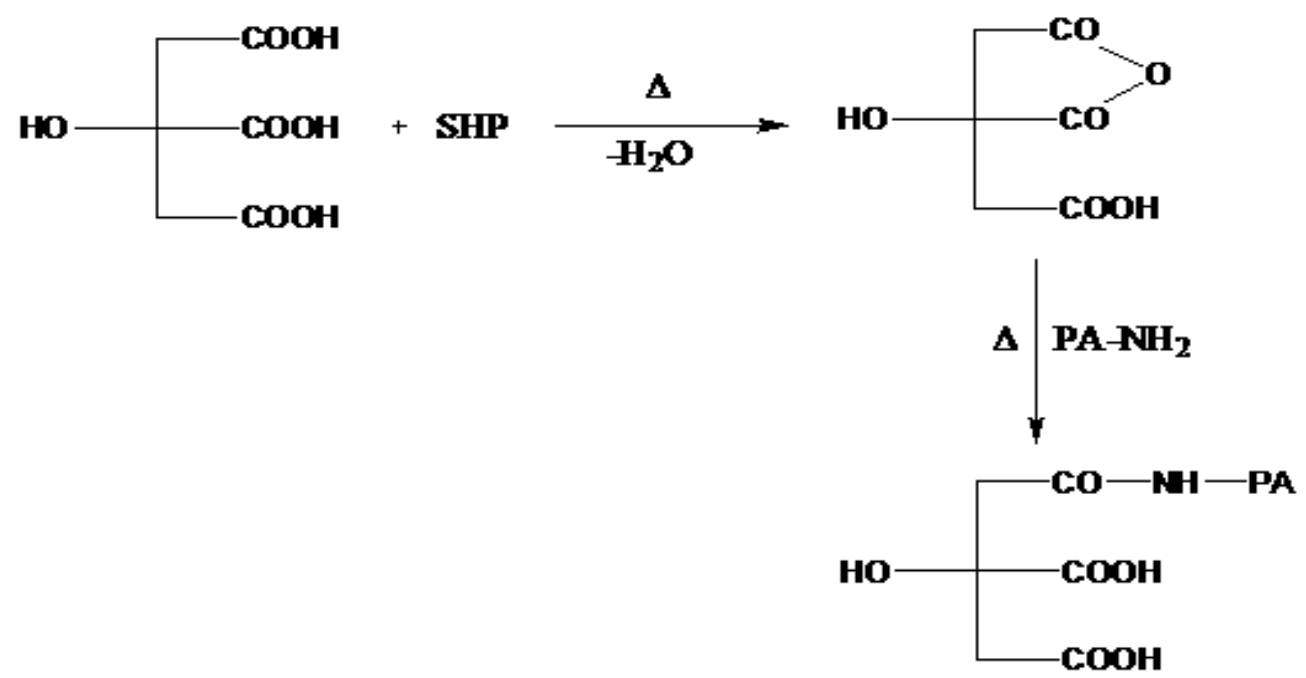

Scheme 1. The chemical reaction between PA-nanofiber and citric acid.

TABLE 3. BET surface area of PA-fiber, PA-nanofiber and modified PA-nanofiber.

\begin{tabular}{cc}
\hline Sample & BET Surface $\operatorname{area~}\left(\mathbf{m}^{2} / \mathbf{g}\right)$ \\
\hline PA-fiber & 18.18 \\
PA-nanofiber & 262.27 \\
Modified PA-nanofiber & 80.28 \\
\hline
\end{tabular}

Egypt. J. Chem. 61, No.5 (2018) 
process is resulted in fiber diameter increase and reduce the surface area[42].

\section{Adsorption study \\ Effect of solution $\mathrm{pH}$}

Solution $\mathrm{pH}$ affects the extent of adsorption by altering the adsorbent-adsorbate interface interactions, and adsorption mechanism and kinetics through changing the electric charges of the functional groups of both adsorbent and adsorbates [27, 45]. Fig. 4 shows that solution $\mathrm{pH}_{\mathrm{o}}$ has a significant effect on the amount of $\mathrm{MB}$ adsorbed for both PA-nanofiber and modified PA-nanofiber. $13.8 \%$ and $51.6 \%$ more MB was removed by $\mathrm{PA}$-nanofiber and modified PAnanofiber, respectively, when the solution $\mathrm{pH}_{\mathrm{o}}$ was increased from 3 to 7 . But further increase in the solution $\mathrm{pH}_{\mathrm{o}}$ to 9 has insignificant effect on the $\mathrm{R} \%$. This trend might be attributed to the fact that ionic interaction is the driving force for the adsorption of the cationic dye MB [27]. At $\mathrm{pH}$ 3 most of the nanofiber mat surface functional groups were probably protonated, accordingly, repel the cationic $\mathrm{MB}$ molecules. In addition, the hydronium ions, produced at $\mathrm{pH}_{\mathrm{o}} 3$, competes for the $\mathrm{MB}$ for the available adsorption sites on the nanofiber mat surfaces. However, as the $\mathrm{pH}_{\mathrm{o}}$ increases the nanofiber mat surface become negatively charged due to the presence of electron pair of $\mathrm{N}$ of the polyamide, and the deprotonation of the $\mathrm{COOH}$ groups introduced by $\mathrm{CA}$ modification in case of modified PA-nanofiber. Consequently, $\mathrm{MB}$ are electrostatically attracted to the nanofiber mat resulting in higher $\mathrm{R} \%$. In addition, the negative charges on the nanofiber mat surface repel each other causing expansion of the network and consequently increasing the $\mathrm{MB}$ removal $[27,46,47]$.

Noteworthy that, the raw PA-fiber was unable to remove $\mathrm{MB}$ at the studied solution $\mathrm{pH}$. But when the PA-fiber was converted to a PAnanofiber it was able to remove about $14 \%$ of $\mathrm{MB}$ at $\mathrm{pH}_{\mathrm{o}} 7$, likely due to spreading the amide group over a higher surface compared to the PA-fiber (see Table 3). Further modification of the PAnanofiber with CA causes a tremendous increase in the $\mathrm{R} \%$ of $\mathrm{MB}$ (reaching about $55 \%$, about 4 times higher than the PA-nanofiber) although the surface area of the modified PA-nanofiber was significantly lower than the PA-nanofiber (see Table 3). These results imply that the carboxylic groups introduced by CA modification play key role in the adsorption of MB. Also, Fig 4 shows that the adsorption process is quick at the first 10 minutes, then it slows down reaching a maximum value at about 60 minutes and remains constant thereafter.

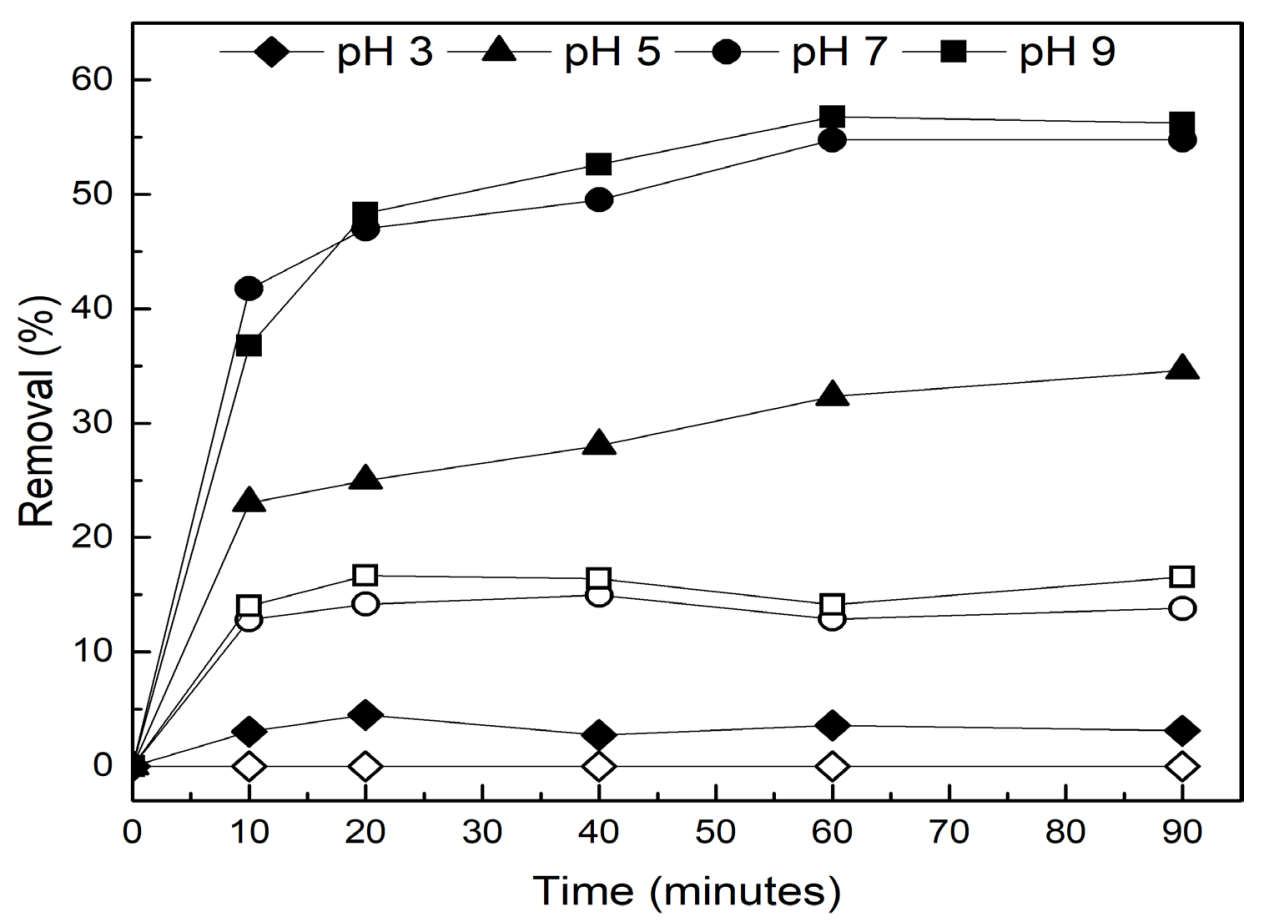

Fig. 4. Removal percentage of $\mathrm{MB}$ at different $\mathrm{pHo}$ as a function of contact time.

(Solid symbols $=$ modified PA-nanofiber, open symbols $=$ PA-nanofiber, $\mathrm{Ci}=\mathbf{5} \mathrm{mg} / \mathrm{L}$ and nanofiber mat dosage $=0.1 \mathrm{~g} / \mathrm{L})$.

Egypt. J. Chem. 61, No.5 (2018) 
Based on these findings, the rest of adsorption experiments were performed at $\mathrm{pH}_{\mathrm{o}} 7$ and contact time 60 minutes.

\section{Effect of nanofiber mat dosage}

Figure 5a shows that the amount of MB removed increases monotonously with increasing the nanofiber mat dosage reaching $23 \%$ and $90 \%$ for PA-nanofiber and modified PAnanofiber, respectively, when the applied dosage was $1 \mathrm{~g} / \mathrm{L}$. This trend is owing to increasing both the surface area and adsorption sites with the nanofiber mat dosage [45-47]. Contrary, the $q_{e}$ dramatically decreased with increasing the nanofiber mat dosage (Fig. 5b), possibly due to availability of large number of adsorption sites which cause unsaturation of some of these sites throughout the adsorption process [26, 27]. Two more investigations can be extracted from Fig. 5a. First, increasing the modified PAnanofiber dosage to $1 \mathrm{~g} / \mathrm{L}$ makes the adsorption process equilibrates faster probably due to the presence of a large number of readily available adsorption sites. Second, under the same conditions, modified PA-nanofiber removes higher percentage of $\mathrm{MB}$ compared with PAnanofiber, which signifies the importance of CA modification. Finally, it worth mentioning that the PA-fiber was unable to remove MB even at a dosage of $2 \mathrm{~g} / \mathrm{L}$. Further experiments were made using nanofiber mat dosage of $1 \mathrm{~g} / \mathrm{L}$.

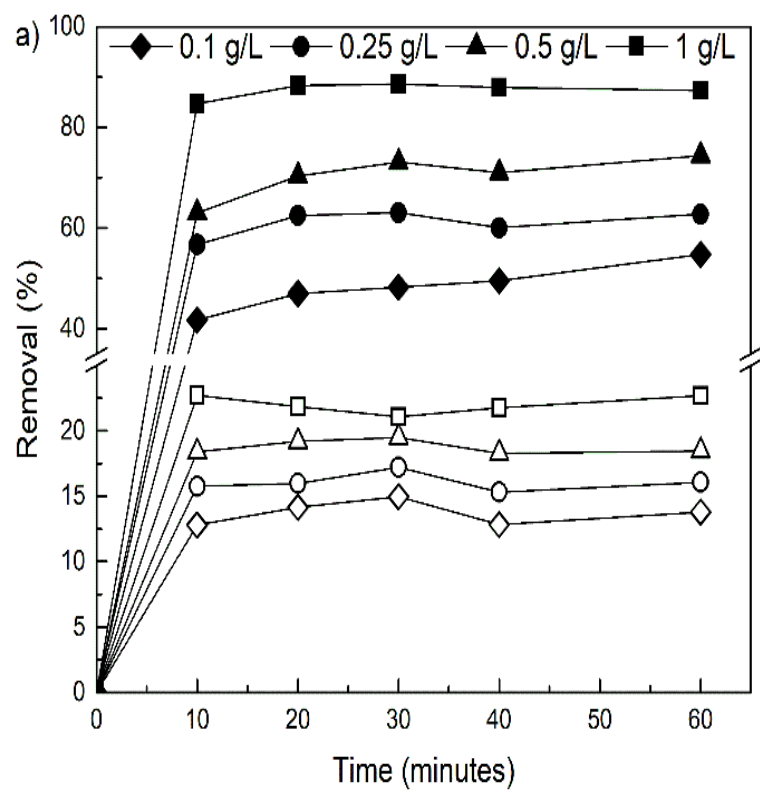

\section{Adsorption kinetics}

Figure 6a showed that the adsorption of MB by $1 \mathrm{~g} / \mathrm{L}$ nanofiber mat is a rapid process that reaches equilibrium in 10 minutes suggesting that the mass transfer rate was very fast. This might be due to the pervasive of the amide groups over a high surface area of the PA-nanofiber and the presence of a large number of carboxylic groups in the modified PA-nanofiber that coordinate with MB. Figure $6 a$ and $b$ displays the fitted plots of the experimental data of the nanofiber mat with the pseudo-first-order model, and pseudo-second-order model, respectively. The driven kinetic parameters are tabulated in Table 4. It can be observed that the plots of the pseudofirst-order model (Fig. 6a) show a non-linear relation. Furthermore, the very low correlation coefficient $\left(\mathrm{R}^{2}\right)$ and disagreement between the expermental $q_{e}\left(q_{\text {e(exp) }}\right)$ and calculated $q_{e}\left(q_{e(\text { calc })}\right)$ (Table 4) revealed the poor fitting of the pseudofirst-order model to the experimental data. On the other hand, the plots of the pseudo-secondorder model (Fig. 6b) show a good linear relation with a high $\mathrm{R}^{2}$ of 0.99 (Table 4 ). In addition, the $q_{\text {e(calc) }}$ was very close to the $q_{\text {e(exp) }}$. Therefore, it can be concluded that the adsorption process can be satisfactorily described by the pseudo-secondorder model. This implies that the adsorption of MB on the nanofiber mat was a chemisorption process and that it involves valence forces between the nanofiber mat and MB [27, 28, 48].

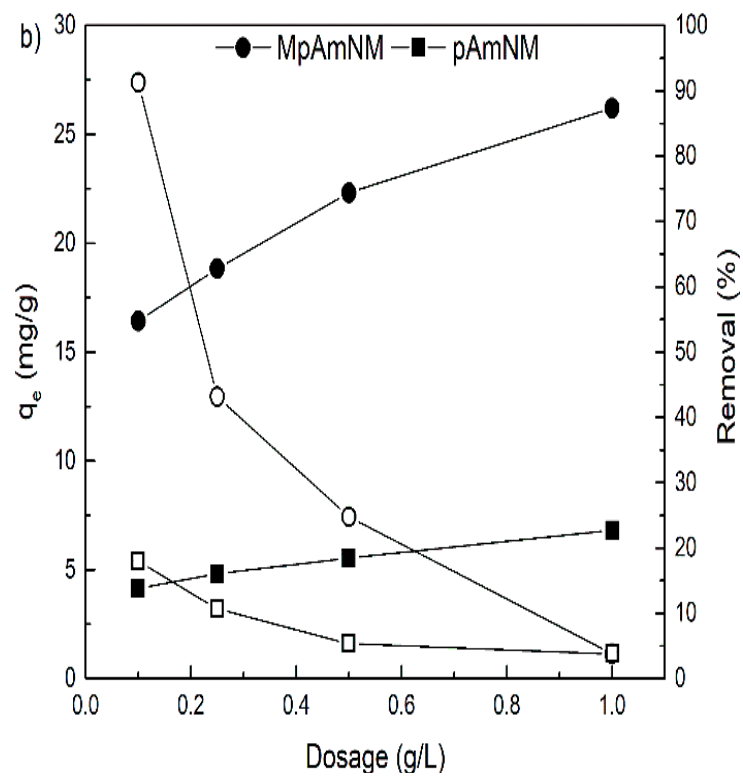

Fig.5. a) Removal percentage of MB at different adsorbent dosage as a function of contact time (Solid symbols $=$ modified PA-nanofiber, open symbols $=$ PA-nanofiber, $\mathrm{Ci}=5 \mathrm{mg} / \mathrm{L}$ and $\mathrm{pHo}=7$ ), and b) variation of $\mathbf{R} \%$ vs qe as a function of nanofiber mat dosage (Solid symbols $=\mathbf{R} \%$, open symbols $=q \mathrm{e}, \mathrm{Ci}=\mathbf{5} \mathrm{mg} / \mathrm{L}$, $\mathrm{pHo}=7$, and contact time $=\mathbf{6 0}$ minutes $)$. 

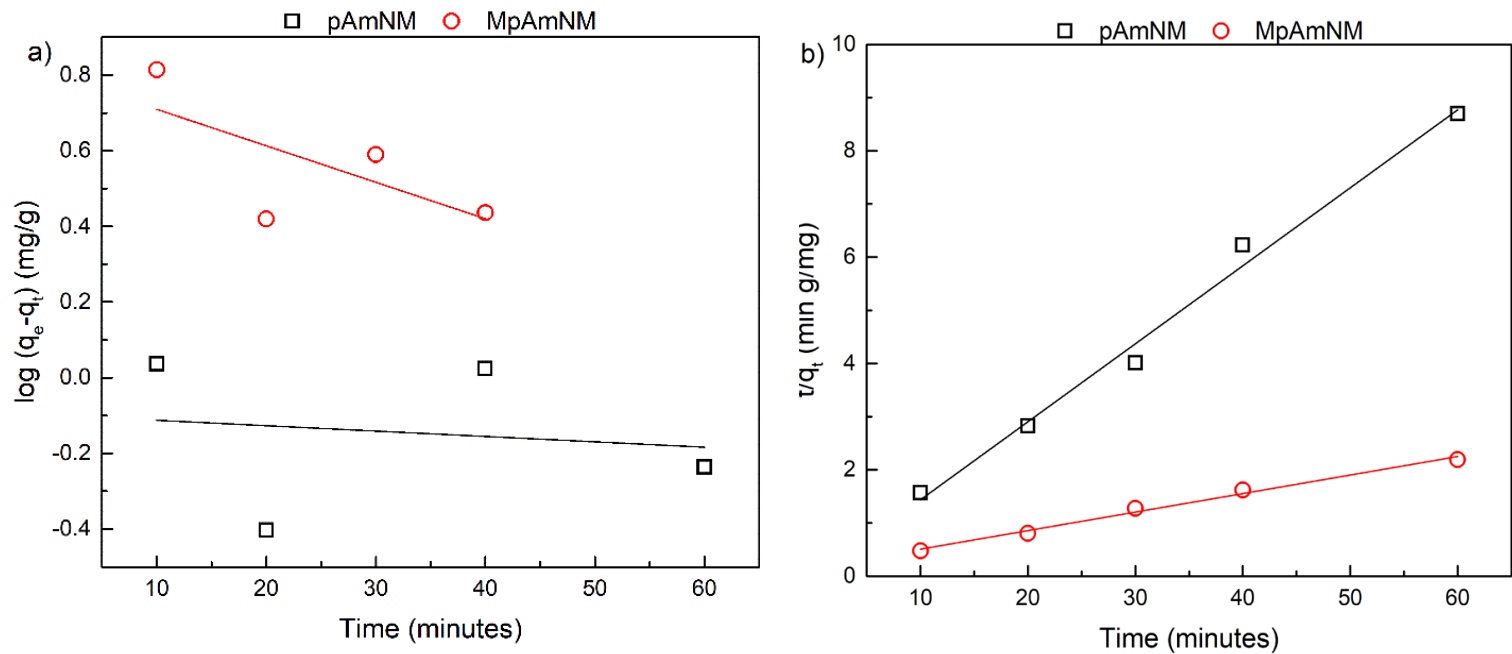

Fig. 6. Adsorption kinetics models; a) pseudo-first-order, and b) pseudo-second-order.

TABLE 4. Calculated constants for the kinetic models.

\begin{tabular}{llcc}
\hline & & PA-nanofiber & $\begin{array}{c}\text { modified PA- } \\
\text { nanofiber }\end{array}$ \\
\hline & $q_{e(e x p)}$ & 7.48 & 27.39 \\
Pseudo-first-order & $\mathrm{R}^{2}$ & 0.03 & 0.46 \\
& $\mathrm{k}_{1}$ & 0.004 & 0.022 \\
Pseudo-second-order & $q_{e(c a l c)}$ & 6.40 & 1.16 \\
& $\mathrm{R}^{2}$ & 0.99 & 0.99 \\
& $\mathrm{k}_{2}$ & 0.78 & 0.01 \\
& $q_{e(c a l c)}$ & 6.82 & 28.74 \\
\hline
\end{tabular}

\section{Adsorption isotherms}

The regression plots of Freundlich, Langmuir, and D-R models are displayed in Fig.7 a, b and c, respectively. The extracted parameters are listed in Table 5. For the PA-nanofiber, the $\mathrm{R}^{2}$ of Freundlich is higher than that of Langmuir suggesting that the Freundlich model can explain the adsorption characteristics of MB onto PAnanofiber satisfactorily. Consequently, MB might form a multilayer on the PA-nanofiber surface. In addition, it is known that the value of $n$ indicates the favorability and the nature of adsorption process [47]. In this study the $n$ value is higher than unity thus the adsorption is favorable and might be chemisorption process.

On the other hand, for the modified PAnanofiber, the $\mathrm{R}^{2}$ of the Langmuir model is higher than that of the Freundlich model so Langmuir model can well interpret the equilibrium data. Accordingly, the modified PA-nanofiber surface is homogenous with a finite number of adsorption sites and MB adsorption is driven by monolayer formation [27, 49]. The Langmuir equilibrium parameter $\left(R_{L}\right)$ was calculated according to Eq. 9 to determine the favorability of $\mathrm{MB}$ adsorption on modified PA-nanofiber. The adsorption process is unfavorable if $R_{L}>1$, linear if $R_{L}=1$, favorable if $0<R_{L}>1$, and irreversible if $R_{L}=0$ [50].

$$
R_{L}=\frac{1}{\left(1+k_{L} C_{i}\right)}
$$

The calculated $R_{L}$ values were ranging between 0.09-0.38 suggesting that the adsorption of $\mathrm{MB}$ on modified PA-nanofiber is a favorable and reversible process.

Noticeably, the $\mathrm{R}^{2}$ of the $\mathrm{D}-\mathrm{R}$ model (Table 5) fits reasonably the adsorption data for both nanofiber mat. It has been reported that the D-R sorption energy $(E)$ constant informs either the adsorption mechanism is physical or chemical. $E$ value ranging from 8 to $16 \mathrm{~kJ} / \mathrm{mol}$, indicates chemisorption, while $E$ value less than $8 \mathrm{~kJ} / \mathrm{mol}$, indicates physisorption $[51,52]$. In this study, the calculated values of $E$ for both nanofiber mat (Table 5) indicate that the adsorption is a chemisorption process.

Egypt. J. Chem. 61, No.5 (2018) 

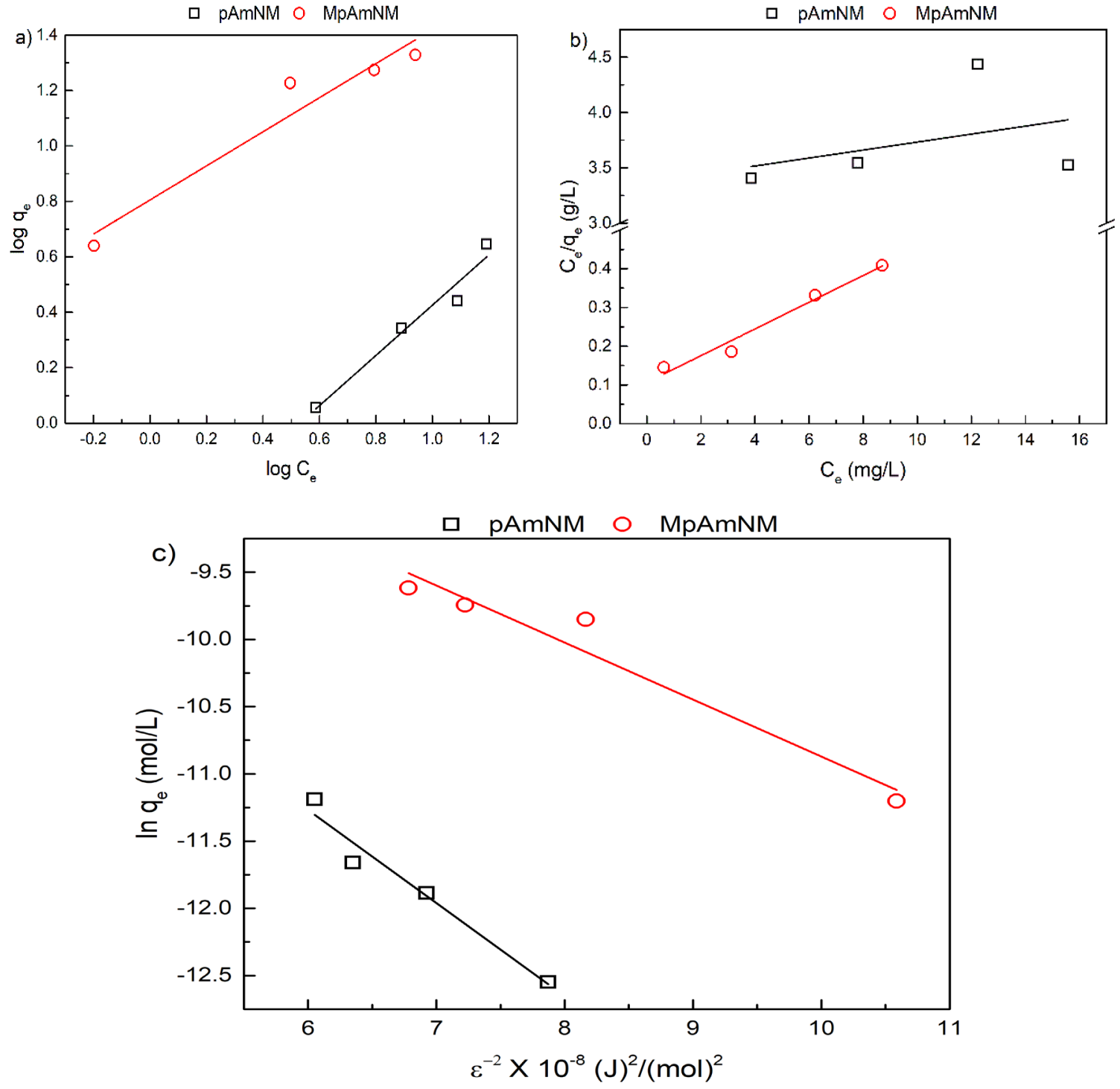

Fig.7. Adsorption isotherms models; a) Freundlich, b) Langmuir and c) D-R.

TABLE 5. Calculated constants for the isotherm models.

\begin{tabular}{llll}
\hline & & PA-nanofiber & modified PA-nanofiber \\
\hline Freundlich & $\mathrm{R}^{2}$ & 0.96 & 0.94 \\
& $k_{F}$ & 0.33 & 6.38 \\
& $n$ & 1.10 & 1.63 \\
Langmuir & $\mathrm{R}^{2}$ & 0.15 & 0.97 \\
& $q_{L}$ & 27.78 & 28.99 \\
& $k_{L}$ & 0.01 & 0.32 \\
D-R & $\mathrm{R}^{2}$ & 0.96 & 0.95 \\
& $\mathrm{E}$ & 8.50 & 10.86 \\
\hline
\end{tabular}

Egypt. J. Chem. 61, No.5 (2018) 


\section{Conclusions}

Electrospinning technique was accompanied by chemical modification with citric acid to produce the low-cost nanofibers based on PA. After systematic study for electrospinning conditions, the optimum conditions observed were solution concentration $18 \%$, fixed distance $25 \mathrm{~cm}$ and applied voltage $20 \mathrm{KV}$. The fabricated PA-nanofiber was modified with CA to improve its adsorption capacity toward MB. Based on the obtained results, the optimum parameters selected for the modification process were $8 \% \mathrm{CA}$, curing temperature at $130{ }^{\circ} \mathrm{C}$ for $5 \mathrm{~min}$ and the catalyst concentration is $8 \%$. The ATR-FTIR shows two new peaks which might refer to the formation of the new amide (CO-NH). The BET surface area of PA-fiber, PA-nanofiber and modified PA-nanofiber with CA shows a remarkable increase in the value of surface area for nanofiber compared to the regular PA-fiber.

The MB adsorption study inferred that the initial $\mathrm{pH}$ as well as the nanofiber mat dosage has a remarkable effect on the amount of the adsorbed dye, which increases monotonously with $\mathrm{pH}$ and nanofiber mat dosage. At a dosage of $1 \mathrm{~g} / \mathrm{L}$, only 10 minutes were sufficient to reach the equilibrium with about $23 \%$ and $90 \%$ of MB adsorbed on PAnanofiber and modified PA-nanofiber, respectively. The adsorption kinetics for both nanofiber mat was best described by the pseudo-second-order model. The isotherm data of PA-nanofiber was fitted well to Freundlich model while those of the modified PA-nanofiber was fitted well to Langmuir model. The adsorption is a favorable process that takes place chemically by valence forces between the nanofiber mat and MB.

\section{Conflict of Interest}

The authors declare that they have no conflict of interest.

\section{References}

1. Ucar, M. and Y. Wang, Utilization of recycled post consumer carpet waste fibers as reinforcement in lightweight cementitious composites. International Journal of Clothing Science and Technology, 23(4), 242-248 (2011).

2. Chen, H.-L. and L.D. Burns, Environmental analysis of textile products. Clothing and Textiles Research Journal, 24(3), 248-261(2006).

3. Ryu, Y.J., H.Y. Kim, K.H. Lee, H.C. Park, and D.R. Lee, Transport properties of electrospun nylon 6 nonwoven mats. European Polymer Journal, 39(9), 1883-1889(2003).
4. Guerrini, L.M., M.C. Branciforti, T. Canova, and R.E.S. Bretas, Electrospinning and characterization of polyamide 66 nanofibers with different molecular weights. Materials Research, 12(2), 181-190 (2009).

5. Chowdhury, M. and G. Stylios, Effect of experimental parameters on the morphology of electrospun Nylon 6 fibres. International Journal of Basic \& Applied Sciences, 10(6), 70-78 (2010).

6. Nirmala, R., H.R. Panth, C. Yi, K.T. Nam, S.-J. Park, H.Y. Kim, and R. Navamathavan, Effect of solvents on high aspect ratio polyamide- 6 nanofibers via electrospinning. Macromolecular Research, 18(8), 759-765 (2010).

7. Zhao, R., Y. Wang, X. Li, B. Sun, and C. Wang, Synthesis of $\beta$-cyclodextrin-based electrospun nanofiber membranes for highly efficient adsorption and separation of methylene blue. ACS Applied Materials \& Interfaces, 7(48), 2664926657 (2015).

8. Borhani, S., Removal of Reactive Dyes from Wastewater using Cyclodextrin Functionalized Polyacrylonitrile Nanofibrous Membranes. Journal of Textiles and Polymers, 4(1), 45-52 (2016).

9. Sarayu, K. and S. Sandhya, Current technologies for biological treatment of textile wastewater-a review. Applied Biochemistry and Biotechnology, 167(3), 645-661(2012).

10. Hamdaoui, O., Batch study of liquid-phase adsorption of methylene blue using cedar sawdust and crushed brick. Journal of Hazardous Materials, 135(1), 264-273(2006).

11. Yan, J., Y. Huang, Y.-E. Miao, W.W. Tjiu, and T. Liu, Polydopamine-coated electrospun poly (vinyl alcohol)/poly (acrylic acid) membranes as efficient dye adsorbent with good recyclability. Journal of Hazardous Materials, 283, 730-739 (2015).

12. Rafatullah, M., O. Sulaiman, R. Hashim, and A. Ahmad, Adsorption of methylene blue on lowcost adsorbents: a review. Journal of Hazardous Materials, 177(1), 70-80 (2010).

13. Yao, Y., F. Xu, M. Chen, Z. Xu, and Z. Zhu, Adsorption behavior of methylene blue on carbon nanotubes. Bioresource Technology, 101(9), 30403046 (2010).

14. Mak, S.-Y. and D.-H. Chen, Fast adsorption of methylene blue on polyacrylic acid-bound iron oxide magnetic nanoparticles. Dyes and Pigments,

Egypt. J. Chem. 61, No.5 (2018) 
61(1), 93-98 (2004).

15. Wang, L., J. Zhang, and A. Wang, Removal of methylene blue from aqueous solution using chitosan-g-poly (acrylic acid)/montmorillonite superadsorbent nanocomposite. Colloids and Surfaces A: Physicochemical and Engineering Aspects, 322(1), 47-53 (2008).

16. Aluigi, A., F. Rombaldoni, C. Tonetti, and L. Jannoke, Study of Methylene Blue adsorption on keratin nanofibrous membranes. Journal of Hazardous Materials, 268, 156-165 (2014).

17. Wang, J., K. Pan, Q. He, and B. Cao, Polyacrylonitrile/polypyrrole core/shell nanofiber mat for the removal of hexavalent chromium from aqueous solution. Journal of Hazardous Materials, 244-245, 121-129 (2013).

18. Rastegar, H., S. Shoeibi, H. Yazdanpanah, M. Amirahmadi, A.M. Khaneghah, F.B. Campagnollo, and A.S. Sant'Ana, Removal of aflatoxin B 1 by roasting with lemon juice and/or citric acid in contaminated pistachio nuts. Food Control, 71, 279-284 (2017).

19. Ouerghemmi, S., S. Degoutin, N. Tabary, F. Cazaux, M. Maton, V. Gaucher, L. Janus, C. Neut, F. Chai, and N. Blanchemain, Triclosan loaded electrospun nanofibers based on a cyclodextrin polymer and chitosan polyelectrolyte complex. International Journal of Pharmaceutics, 513(1), 483-495 (2016).

20. Dos Santos, V.C., J.V. De Souza, C.R. Tarley, J. Caetano, and D.C. Dragunski, Copper ions adsorption from aqueous medium using the biosorbent sugarcane bagasse in natura and chemically modified. Water, Air, \& Soil Pollution, 216(1-4), 351-359 (2011).

21. Altun, T. and E. Pehlivan, Removal of Cr (VI) from aqueous solutions by modified walnut shells. Food Chemistry, 132(2), 693-700 (2012).

22. Leyva-Ramos, R., L. Landin-Rodriguez, S. LeyvaRamos, and N. Medellin-Castillo, Modification of corncob with citric acid to enhance its capacity for adsorbing cadmium (II) from water solution. Chemical Engineering Journal, 180, 113-120 (2012).

23. Han, R., L. Zhang, C. Song, M. Zhang, H. Zhu, and L. Zhang, Characterization of modified wheat straw, kinetic and equilibrium study about copper ion and methylene blue adsorption in batch mode. Carbohydrate Polymers, 79(4), 1140-1149 (2010).
24. Yuh-Shan, H., Citation review of Lagergren kinetic rate equation on adsorption reactions. Scientometrics, 59(1), 171-177(2004).

25. Ho, Y.-S., Review of second-order models for adsorption systems. Journal of Hazardous Materials, 136(3), 681-689 (2006).

26. Wu, L., W. Wan, Z. Shang, X. Gao, N. Kobayashi, G. Luo, and Z. Li, Surface modification of phosphoric acid activated carbon by using nonthermal plasma for enhancement of $\mathrm{Cu}$ (II) adsorption from aqueous solutions. Separation and Purification Technology, 197, 156-169 (2018).

27. Melo, B.C., F.A.A. Paulino, V.A. Cardoso, A.G.B. Pereira, A.R. Fajardo, and F.H.A. Rodrigues, Cellulose nanowhiskers improve the methylene blue adsorption capacity of chitosan-g-poly(acrylic acid) hydrogel. Carbohydrate Polymers, 181, 358367 (2018).

28. Ho, Y.S. and G. McKay, Pseudo-second order model for sorption processes. Process Biochemistry, 34(5), 451-465 (1999).

29. Langmuir, I., The adsorption of gases on plane surfaces of glass, mica and platinum. Journal of the American Chemical Society, 40(9), 1361-1403 (1918).

30. Freundlich, H.M.F., Over the adsorption in solution. Journal of Physical Chemistry, 57, 385470 (1906)

31. Dubinin, M.M. and L.V. Radushkevich, The equation of the characteristic curve of the activated charcoal. Proc. Acad. Sci. USSR Phys. Chem. Sect., 55, 331-337 (1947).

32. Lessa, E.F., M.S. Gularte, E.S. Garcia, and A.R. Fajardo, Orange waste: A valuable carbohydrate source for the development of beads with enhanced adsorption properties for cationic dyes. Carbohydrate Polymers, 157, 660-668 (2017).

33. Vaz, M.G., A.G.B. Pereira, A.R. Fajardo, A.C.N. Azevedo, and F.H.A. Rodrigues, Methylene Blue Adsorption on Chitosan-g-Poly(Acrylic Acid)/ Rice Husk Ash Superabsorbent Composite: Kinetics, Equilibrium, and Thermodynamics. Water, Air, \& Soil Pollution, 228(1), 14 (2016).

34. Supaphol, P., C. Mit-Uppatham, and M. Nithitanakul, Ultrafine electrospun polyamide-6 fibers: Effect of emitting electrode polarity on morphology and average fiber diameter. Journal of Polymer Science Part B: Polymer Physics, 
43(24), 3699-3712 (2005).

35. Homayoni, H., S.A.H. Ravandi, and M. Valizadeh, Electrospinning of chitosan nanofibers: Processing optimization. Carbohydrate Polymers, 77(3), 656661 (2009).

36. Matabola, K. and R. Moutloali, The influence of electrospinning parameters on the morphology and diameter of poly (vinyledene fluoride) nanofiberseffect of sodium chloride. Journal of Materials Science, 48(16), 5475-5482 (2013).

37. Nirmala, R., K.T. Nam, S.-J. Park, Y.-S. Shin, R. Navamathavan, and H.Y. Kim, Formation of high aspect ratio polyamide- 6 nanofibers via electrically induced double layer during electrospinning. Applied Surface Science, 256(21), 6318-6323 (2010).

38. Fu, Q., X. Wang, Y. Si, L. Liu, J. Yu, and B. Ding, Scalable fabrication of electrospun nanofibrous membranes functionalized with citric acid for high-performance protein adsorption. ACS Applied Materials \& Interfaces, 8(18), 1181911829 (2016).

39. Wing, R.E., Corn fiber citrate: preparation and ion-exchange properties. Industrial Crops and Products, 5(4), 301-305 (1996).

40. Ibrahim, N., M. Abo-Shosha, E. Elnagdy, and M. Gaffar, Eco-friendly durable press finishing of cellulose-containing fabrics. Journal of Applied Polymer Science, 84(12), 2243-2253 (2002).

41. Wing, R.E., Starch citrate: preparation and ion exchange properties.Starch-Stärke, 48(7-8), 275279 (1996).

42. Kayaci, F., Z. Aytac, and T. Uyar, Surface modification of electrospun polyester nanofibers with cyclodextrin polymer for the removal of phenanthrene from aqueous solution. Journal of Hazardous Materials, 261, 286-294 (2013).

43. Nirmala, R., R. Navamathavan, M.H. El-Newehy, and H.Y. Kim, Preparation and characterization of electrospun ultrafine polyamide- 6 nanofibers. Polymer International, 60(10), 1475-1480 (2011).

44. Cheval, N., N. Gindy, C. Flowkes, and A. Fahmi, Polyamide 66 microspheres metallised with in situ synthesised gold nanoparticles for a catalytic application. Nanoscale Research Letters, 7(1), 182 (2012).

45. Radwan, E.K., H.H.A. Ghafar, A.S. Moursy, C.H. Langford, A.H. Bedair, and G. Achari, Adsorptive removal of hazardous organic water pollutants by humic acid-carbon hybrid materials: kinetics and isotherm study. Desalination and Water Treatment, 80, 297-305 (2017).

46. Ghafar, H.H.A., M.A. Embaby, E.K. Radwan, and A.M. Abdel-Aty, Biosorptive removal of basic dye methylene blue using raw and $\mathrm{CaCl}_{2}$ treated biomass of green microalga Scenedesmus obliquus. Desalination and Water Treatment, $\mathbf{8 1}$, 274-281 (2017).

47. Ghafar, H., T. Salem, E. Radwan, A.A. El-Sayed, M. Embaby, and M. Salama, Modification of Waste Wool Fiber as Low Cost Adsorbent for The Removal of Methylene Blue from Aqueous Solution. Egyptian Journal of Chemistry, 60(3), 395-406 (2017).

48. Mayakaduwa, S.S., P. Kumarathilaka, I. Herath, M. Ahmad, M. Al-Wabel, Y.S. Ok, A. Usman, A. Abduljabbar, and M. Vithanage, Equilibrium and kinetic mechanisms of woody biochar on aqueous glyphosate removal. Chemosphere, 144, 25162521 (2016).

49. Singh, T. and R. Singhal, Reuse of a waste adsorbent poly(AAc/AM/SH)-Cu superabsorbent hydrogel, for the potential phosphate ion removal from waste water: Matrix effects, adsorption kinetics, and thermodynamic studies. Journal of Applied Polymer Science, 129(6), 3126-3139 (2013).

50. Mahida, V.P. and M.P. Patel, Removal of some most hazardous cationic dyes using novel poly (NIPAAm/AA/N-allylisatin) nanohydrogel. Arabian Journal of Chemistry, 9(3), 430-442 (2016).

51. El-Wakeel, S.T., E.K. Radwan, H.H.A. Ghafar, and A.S. Moursy, Humic acid-carbon hybrid material as lead (II) ions adsorbent. Desalination and Water Treatment, 74, 216-223 (2017).

52. Embaby, M.A., H.H.A. Ghafar, M.M. Shakdofa, N.M. Khalil, and E.K. Radwan, Removal of iron and manganese from aqueous solution using some clay minerals collected from Saudi Arabia. Desalination and Water Treatment, 65, 259-266 (2017).

(Received 19/6/2018; accepted 11/7/2018) 

تصنيع ، وتوصيف ، وقياس قدرة امتصاص الصبغة لألياف النانو المعلده والمعاد تلويرها

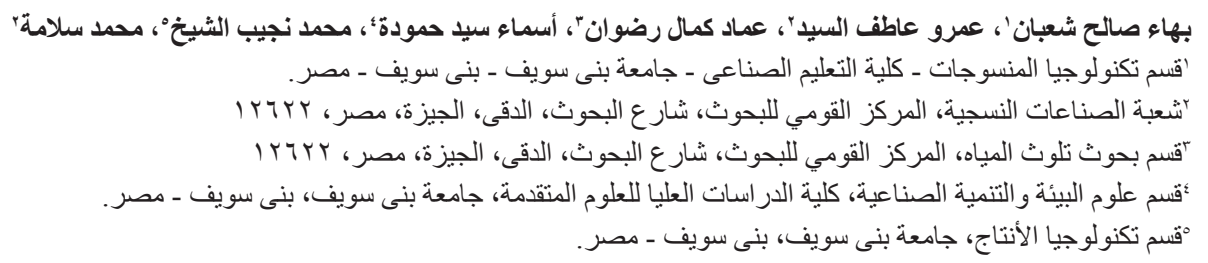

يهذف هذا البحث الى إستخدام تقنية الغزل الكهربائي المصحوب بالمعالجة الكيميائية لإنتاج مو اد امتصاص منخفضة التكلفة

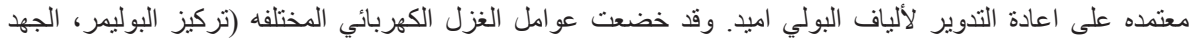

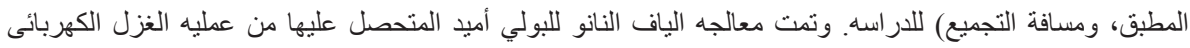

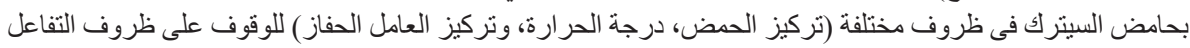

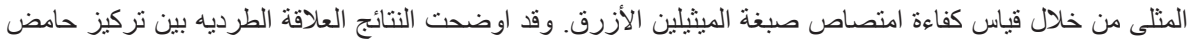

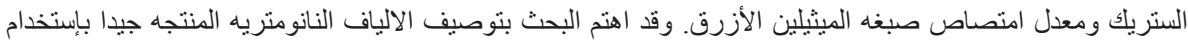

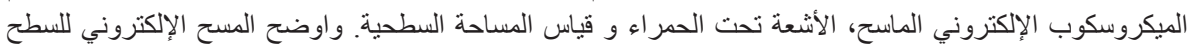

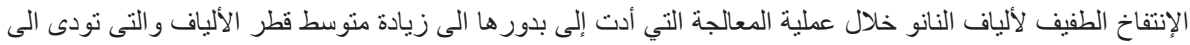

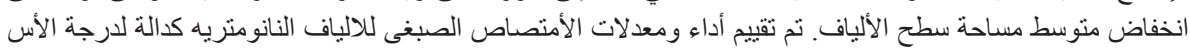

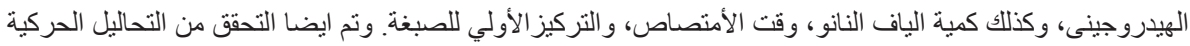

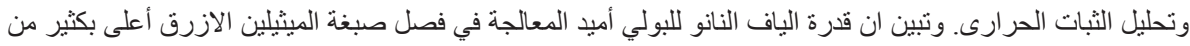

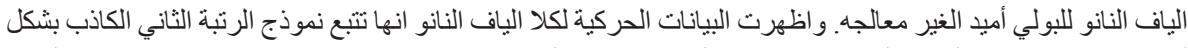

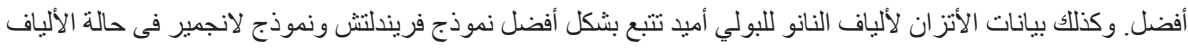

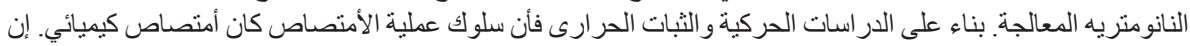

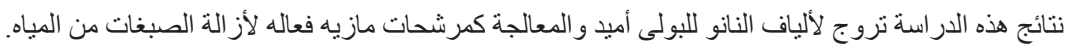

